\title{
Evaluation of Training and Development: An Analysis of Various Models
}

\author{
Harshit Topno
}

\begin{abstract}
Training and development enhances efficiency and develops a systematic way of performing duties and assigned tasks. Moreover it bridges the gap between job requirement and employees present specification. Training like any other organizational activity requires time, energy and money. It's an investment in employees' productivity and retention by providing for career progression and employees job satisfaction over the long time. Therefore the organisation needs to know whether their investment is being spent effectively or not. For this continuous evaluation of training and development is necessary. Evaluation of training and development means assessment of the impact of training on trainee's performance and behaviour. The present paper is descriptive in nature falls under the category of general review for understanding the conceptual framework of evaluation, its needs and purpose and the various models adopted by organisation for evaluation purpose. Finally in conclusive remark paper suggests the most widely used model and what are the issues which lead to ignorance of evaluation as well as in the course of evaluation.
\end{abstract}

Keywords: Evaluation, Expenditure, Models, Organisation, Training and Development

\section{Introduction}

Training like any other organizational activity requires time, energy and money. It's a critical investment in a strategy that leads to internal promotion, succession planning and employees development. It's an investment in employees' productivity and retention by providing for career progression and employees job satisfaction over the long time (Bowes, 2008). Therefore the organisation needs to know whether their investment is being spent effectively or not. For this continuous evaluation of training and development is necessary. Evaluation of training and development means assessment of the impact of training on trainee's performance and behaviour.

Due to increasing expenditure of training and development, number of organisations is raising questions concerning the return on these investments. There is a decreasing willingness to spend money on faith and an increasing pressure to justify training and development costs. Baldwin and Ford have estimated that "not more than 10 percent of training and development expenditure actually results in transfer to the job." In this context, it is imperative for those in the field to focus on evaluation of training and development and properly demonstrate and communicate to management that training efforts are making worthwhile contribution.

\section{Evaluation: A Comprehensive Approach}

Evaluation of training and development is the most essential aspect of training programme. Generally all good training and development programmes start with identification of training and development needs and ends with evaluation of training (Gopal, 2009). Training evaluation ensures that whether candidates are able to implement their learning in their respective work place or to the regular routines (Nagar, 2009).

Phillips (1991) defined evaluation as a systematic process to determine the worth, value or meaning of something. Holli and Colabrese (1998) defined evaluation as comparisons of an observed value or quality to a standard or criteria of comparison. It is the process of forming value judgements about the quality of programmes, products and goals. Boulmetis and Dutwin (2000) defined evaluation as the systematic process of collecting and analyzing data in order to determine whether and to what degree objectives were or are being achieved. Schalok (2001) defined effectiveness evaluation as the determination of the extent to which a programme has met its stated performance goals and objectives. Evaluation, in its crudest form, is the comparison of objectives with effects answer the question of how far training has achieved its objectives. Evaluation can be difficult because it is often hard to set measurable objectives and even harder to collect the information on the results or to decide on the level at which the evaluation should be made.

The process of evaluating training and development has been defined by Hamblin (1974) as, "any attempt to obtain information (feedback) on the effects of training programme and to assess the value of the training in the light of that information. In other words evaluation may be defined as the systematic collection and assessment of information for deciding how best to utilise available training resources in order to achieve organisational goals. In other words training evaluation refers to process of collecting and measuring the outcomes needed to determine whether training is effective. The evaluation design refers to the collection of 
information - including what, when, how and from whom - that will be used to determine the effectiveness of the training programme (Noe, 2008).

Evaluation of training and development involves assessing whether it is achieving its objectives, it is effective or not. Training effectiveness refers to the benefits that the company and the trainees receive from training. Benefits for trainees may include learning new skills or behaviour. Benefits for the company may include increased sales and more satisfied customers. However, it is very difficult to measure the effectiveness of training and development because of its abstract nature and long term impact on the trainees and the organisation (Prasad, 2005).

\section{Literature Review}

Ramachandran (2010) has made an analytical study on effectiveness of training programme of different cadre of employees working in a public sector organization. The result reveals that employees differed in effectiveness of training programme on the basis of demographic characters. It is also inferred that experience and education of the employees of the organization is predominating and determining factor in training programme.

Nagar (2009) has viewed that training budgets are growing at a phenomenal pace as organization use training to build required skills, indoctrinate new employees, transform banking culture, merge new acquisitions into the organization and build multiple skills for radically changing jobs. Scholar has made an attempt to study the effectiveness of training programmes being conducted by the commercial banks in public as well as in the private sector based on the responses of their clerical level staff. The results of the study reveal that training programmes of the respondent organizations are generally effective with respect to course duration, library facilities, trainer, teaching and computer aided programme and infrastructure facilities.

Saharan (2011) highlighted that most organization are taking feedback from employees for training effectiveness to maximize its benefits. In the ceaseless drive for a competitive edge, companies subscribe to the belief that smarter, better trained workers increase chances for success. The study expounds the perspective of employees having different qualification and experiences towards objectives behind imparting training in organizations.

Smith (1990) viewed that evaluation of management training courses is a subject much discussed but, superficially carried out. The study finds that there is too great an emphasis on providing an objective evaluation report and too little recognition of subjective and peculiar issues which do not necessarily fit the frame.

Hashim (2001) has made an intensive study that training evaluation is an elusive concept, especially when it comes to practice. The practice of evaluation in training has received a lot of criticism. This criticism is largely explained by the unsystematic, informal and adhoc evaluation that has been conducted by training institution.

Griffin (2010) finds that there is a mismatch between organizations desires to evaluate training and the extent and effectiveness of actual evaluation. There are a numbers of reasons for this including the inadequacy of current methods. The author has proposed a productivity based framework to focus data collection and the utilization of a metric to present results. A metric provides an ideal tool to allow stakeholders informed judgment as to the value of a programme, whether it has met its objectives and what its impact is. Most importantly the approach focuses on the bottom line and draws evaluator's attention to consider what the ultimate overall impact of learning is.

Al-Ajlouni, Athammuh \& Jaradat (2010) viewed that the evaluation of any training programme has certain aims to fulfil. These are concerned with the determination of change in the organizational behaviour and the changes needed in the organizational structure. Scholars asserts that evaluation of any training programme must inform whether the training programme has been able to deliver the goals and objectives in terms of cost incurred and benefit achieved, the analysis of the information is the concluding part of any evaluation programme. They also stressed that the analysis of data should be summarized and then compared with the data of other training programmes similar nature. On the basis of these comparisons, problems and strength should be identified which would help the trainer in his future training programme.

Ogundejl (1991) viewed that evaluation is increasingly being regarded as a powerful tool to enhance the effectiveness of training. Three major approaches to training evaluation: quality ascription, quality assessment and quality control are highlighted. In order to enhance the effectiveness of training, evaluation should be integrated with organizational life.

Hunt \& Baruch (2003) highlighted that some organizations invest a great deal of time and effort in elaborate training programmes designed to improve the so-called soft skills of managing. Yet assessing the effectiveness of such initiatives has been rare. Recent developments in the use of survey feedback have provided a technique for pre and post training assessment. A study, at a leading business school, was designed to assess the impact of interpersonal skills training on top managers. The evaluation of training was based on subordinate feedback conducted before, and six months after training programme took place. The result indicates significant impact on some but not all of the competencies and skill under study.

AL-Athari \& Zairi (2002) has examined the current training evaluation activity and challenges that face Kuwaiti organizations. The study reveals that the majority of respondents, both in government and in 
private sectors, only evaluate their training programme occasionally. The most popular evaluation tools and technique used by government and private sectors were questionnaires. The most common model used by Kuwaiti organizations is the Kirkpatrick model, while the most common level of evaluation for both government and private sector is reaction type.

Iyer, Pardiwalla \& Bathia (2009) briefly explore the various methods of training evaluation to understand the need for training evaluation with emphasis on the Kirkpatrick's model. Scholars concluded that although there are different methods to evaluate training, still training evaluation is the weakest and most under developed aspect of training. Although evaluation is still a grey area, every organization has to move to evaluate return on investment and behaviour to evaluate its training programme in order to justify the investment made in training as well as to improve the training process.

Gopal (2008) examines the evaluation of effectiveness of executive training programmes in Electronic of India Ltd. Scholar carried out evaluation of training in two ways. (1). Individual programme wise evaluation and (2). Overall evaluation of all programmes. The evaluation of training provides useful feedback to the training professional and management as to help in making appropriate and effective one for the next better programme. Therefore evaluation of training is not exactly the end point in the training function. In fact it is a starting point.

Blanchard et al. (2000) studied training evaluation practices at both management and non-management level in Canada through a survey. The survey data indicated that only one-fifth the Canadians organizations evaluated their training as suggested by academic standards. The researchers presented practitioner perspective as a supporting rationale for the survey results.

Ogunu (2002) in his study titled "Evaluation of Management Training and Development Programme of Guinness Nigeria PLC" examined the management training and development programme of Guinness Nigeria PLC, Benin City with a view to ascertaining its relevance, adequacy, and effectiveness. Hypotheses testing in the study revealed that facilities for staff training were adequate for effective training of management staff, training programme for management staff were relevant to the jobs they performed, and the training programme undergone by staff did indeed improve their performance and effectiveness at works.

Srivastava. ET. al. (2001) evaluated the effectiveness of various training, programme offered by the inhouse training centre of Tata Steal, Shavak Nanavati Training Institute (SNTI), India. Effectiveness of training was measured in terms of various outcomes such as satisfaction level, reaction and feedback of participants, and change in performance and behaviour as perceived by participants, their immediate supervisors, and departmental heads. It was found that the satisfaction level of participants, their superiors and divisional heads were above average for all types of programmes. The participants were benefited from the programme but transfer of learning was not as expected from the supervisors.

\section{Training Evaluation: Purpose And Need}

An evaluation of a training programme can help an organisation meet different goals during the life of training programme. Evaluation of training programme has two basic rules aims - assessing training effectiveness, and using it as a training aid. The primary aim of evaluation is to improve training by discovering which training processes are successful in achieving their stated objectives. Since evaluation affects learning, it can also be put to use as a training aid (knowledge of results facilities good learning). The other purposes of training evaluation include the following:

- To determine whether the training and development objectives are being met.

- To determine the effectiveness of the different components of training and development programme (e.g. contents, training aids, facilities and environment, programme schedule, presentation style, the instructor etc.)

- To determine whether the training and development programme justifies the cost.

- To decide who (number and type of potential participants) should participate in future programme.

- To assess which participants gained the most or the least from specific programmes.

- To gain practical insight in order to design, develop and deliver more effective future programmes.

- To conform to policy guidelines and documentation of training and development efforts.

- To check the extent of transfer of learning i.e. the extent to which a trainees applies to his/her job.

- To determine if the training programme maps to the needs the trainees.

Bramley and Newby (1984) identify four main purposes of evaluation.

- Feedback: Linking learning outcomes to objectives and providing a form of quality control;

- Control: Making links from training to organisational activities and to consider cost effectiveness;

- Research: Determining the relationship among learning, training and transfer of training to the job;

- Intervention: The results of the evaluation influence the context in which it occurs; 


\section{Models For Training Evaluation}

There are different models to evaluate training, still training evaluation is the weakest and most under developed aspect of training. There are number of issues which lead to ignorance of evaluation as well as faced in the course of evaluation. It causes expenses that can be ill afforded in a constrained financial area and also it takes time to practice (Iyer, 2009). There are several reasons for underdeveloped evaluation. They are; evaluation means different things to different people, it is perceived to be difficult, tedious and time consuming task which trainers do not like to pursue, people tend to assume the training will simply work, trainers feel threatened by the prospect of an objective evaluation of training and its outcome (Sims, 1993). Scholar states that the main reasons for failure of evaluations are: inadequate planning, lack of objectivity, evaluation errors of some sort, improper interpretation and inappropriate use of results. Other issues are failure to train the evaluators on the techniques of evaluation, inappropriate data gathering instrument and focus on unimportant details.

Different models are used by organisations to evaluate training effectiveness according to the nature and budgets of the business. Some of the commonly used models are as follows:

A. Kirkpatrick Model: This model has been introduced in 1959 by Donald Kirk Patrick. This is a very popular model focuses on measuring four kinds of outcomes or it can be said that outcomes in four levels that should result from a highly effective training programme. Kirkpatrick (1977) divided the evaluation model into four parts: reaction; learning; behaviour and results. Reaction would evaluate how participants feel about the programme they attended. The learning would evaluate the extent to which the trainees learned the information and skills, the behaviour would evaluate the extent to which their job behaviour had changed as a result of attending the training. The results would evaluate the extent to which the results have been affected by the training programme. According to a survey by the American Society for training and development (ASTD), the Kirkpatrick four level evaluation approaches is still the most commonly used evaluation framework among Benchmarking Forum Companies (Bassi \& Cheney, 1997). The main strength of the Kirkpatrick evaluation approach is the focus on behavioural outcomes of the learners involved in the training (Mann \& Robertson, 1996).

The detailed examination of the above mentioned model is as follows:

Reaction level: Programme evaluation involves two general approaches - Formative evaluation also known as internal and summative evaluation also known as external evaluation. Likewise reaction evaluation is a type of formative evaluation when the results are used for programme modification and the redesign of contents, course material and presentations (Antheil \& Casper, 1986; Robinson \& Robinson, 1989). Reaction can also be summative in nature. In such cases, the goal of reaction evaluation is to determine the value, effectiveness or efficiency of a training programme (Smith \& Brandenburg, 1991) and to make decisions concerning programme continuation, termination, expansion, modification or adoption (Worthen \& Sanders, 1987). Summative evaluation provides programme decision makers and potentials customers with judgements about a programme's worth or merit (Worthen, Sanders \& Fitzpatrick, 1997).

The main purpose of reaction evaluation is to enhance the quality of training programmes, which in turn leads to improved performance by measuring the participant's reactions to training programme. This should be measured immediately after the programme. Level one evaluation should not just include reactions towards the overall programme (e.g. did you like the programme.); it should also include measurement of participants' reactions or altitudes towards specific components of the programme such as, the topics, contents, methodology, instructor etc.

The example of evaluations tools and methods suggested by scholars are typically happy sheets, feedback forms based on subjective reaction to the training experiences, Verbal reaction which can be noted and analysed, Post training surveys or questionnaires, online evaluation or grading by delegates, subsequent verbal or written reports given back by delegates to managers back to their jobs etc.

Learning level: Evaluation at this level wants to differentiate between what they already knew prior to training and what they actually learned during the training programme (Jeng \& Hsu, nd.). In other words it can be said that learning evaluation is the measurement of the increase in the knowledge or intellectual capability from before to after the learning experience. Learning outcome can include changes in knowledge, skills or attitudes. Some training events will emphasize knowledge, some will emphasize skills, some will emphasize attitudes and some will emphasize multiple learning outcomes. The Evaluation should focus on measuring what was covered in the training events i.e. learning objectives. So this level's questions will have a pre test before practicum and a post test after practicum. Tools and methods which can be used in evaluating learning level are assessment or tests before and after the training, interviews or observations can be used before or after, although this is time consuming and can be inconsistent. 
Behaviour level: Behaviour evaluation is the extent to which the trainees applied the learning and changed their behaviour, and this can be immediately and several months after the training, depending on the situation. This level evaluation wants to measure the transfer that has occurred in the learner's job behaviour/ job performance due to the training programme. This performance testing is to indicate the learner's skill to apply what he has learned in the classroom. It involves testing the participants' capabilities to perform learned skills while on the job, rather than in the classroom. Change in the job behaviour is difficult to measure because people change in different ways at different times and also it is difficult to quantify and interpret than reaction and learning evaluation. Observation and interview overtime are required to assess change, relevance of change and sustainability of change in behaviour of participants. The opinion of the trainees in the form of self assessment, 360 - degree feedback is useful method to evaluate this level.

Result level: Result level evaluation is the effect on the business or environment resulting from the improved performance of the trainee. Level four outcomes are not limited return on training investment (ROI). It can also include others major results that contribute to the well functioning of an organisation, it includes any outcome that the most people would agree is "good for the business", Outcomes are either changes in financial outcomes (such as positive ROI or increased profits) or changes in the variables that should have a reliability direct effect on financial outcome at the same point of the future.

The intention at this level is to assess the coat vs. benefits of training programme, i.e. organisational impact in terms of reduced costs, improved quality of work, higher productivity, reduction in turnover, improved human relation, increased sales, fewer grievances, lower absenteeism. Higher work morale, fewer accidents, greater job satisfaction etc. Collecting, organising and analysing level four information can be difficult, time consuming and more costly than the other three levels, but the results are often quite worthwhile when viewed in the full context of its value to the organisation.

B. CIPP Evaluation model: CIPP model of programme evaluation is developed by Daniel L. Stufflebeam (1983). It refers to the four phases of evaluation: context evaluation, input evaluation, process evaluation and product evaluation. It is based upon the view that the most important purpose of evaluation is to improve the functioning of a programme.

Context evaluation: It involves evaluation of training and development needs analysis and formulating objectives in the light of these needs. It is aimed at determining the extent to which the goals and objectives of the programme matched the assessed need of the organisation, whether needs assessment is accurately identified an actual and legitimate need of organisation and relevant work culture. Context evaluation is part and parcel of the work undertaken by employees of an organisation.

Input Evaluation: Input evaluation involves an examination of the intended content of the programme. It is designed to assess the extent to which programme strategies, procedures, and activities support the goals and objectives identified in the needs assessment and context evaluation. An input evaluation is therefore an assessment of the programmes action plan. Such an evaluation helps in prescribing the specific activities and strategies and procedures and to ensure that it has been chosen the best approach in terms of the assessed needs and goals and objectives that has been identified. It involves evaluation of determining policies, budgets, schedules and procedures for organising programme.

Process Evaluation: A process evaluation is the critical aspect of programme implementation. It involves evaluation of preparation of reaction sheets, rating scales and analysis of relevant records (Prasad, 2005). Process evaluation is a continual assessment of the implementation of the action plan that has been developed by organisation. It is an ongoing and systematic monitoring of the programme. A process evaluation provides information that can be used to guide the implementation of programme strategies, procedures and activities as well as a means to identify successes and failures. The objectives of process evaluation are

- to provide feedback to organisation and their employees about the extent to which the activities are on schedule are being carried out as planned and using time and resources in an efficient manner;

- to provide guidance for modifying or explicating the programmes action plan as needed, particularly since not all aspects of the plan can be anticipated or planned in advance;

- to assess periodically the extent to which programmes personnel are performing their rules and carting out their responsibilities;

- to provide an extension record of the programmes, how it was implemented and how it compares to what was intended.

Product evaluation: It involves measuring and interpreting the attainment of training and development objectives. In other words it can be said that the purpose of product evaluation is to measure, interpret and judge 
the extent to which an organisation's improvement efforts have achieved their short term and long term goals. It also examines both intended and unintended consequences of improvement efforts.

C. CIRO approach: In 1970, the CIRO model for the evaluation of managerial training was proposed (Warr, Bird \& Rackson, 1970). This model was based on the evaluation of four aspects of training: context, input, reaction and outcomes. According to Tennant, Boonkrong and Roberts (2002), the CIRO model focuses on measurement both before and after the training has been carried out. The main strength of the CIRO model is that the objectives (context) and the training equipment (input) are considered. Context Evaluation focuses on factors such as the correct identification of training needs and the setting of objectives in relation to the organisation's culture and climate. Input evaluation is concerned with the design and delivery of the training activity. Reaction evaluation looks at gaining and using information about the quality of training experience. Outcome evaluation focuses on the achievement gained from the activity and is assessed at three levels: immediate, intermediate and ultimate evaluation. Immediate evaluation attempts to measure changes in knowledge, skills or attitude before a trainee returns to the job. According to Santos and Stuart (2003) intermediate evaluation refers to the impact of training on the job performance and how learning is transferred back into the workplace. Finally, ultimate evaluation attempts to assess the impact of training on departmental or organisational performance in terms of overall results.

D. Phillip's Evaluation approach: In the past decade, training professionals have been challenged to provide evidence of how training financially contributes to business. Phillips (1996) suggested adding another level to Kirk - Patrick's four level evaluation approach to calculate the return on investment (ROI) generated by training. According to James and Roffe (2000), Plillips's five level evaluation approaches translate the worth of training into monetary value which, in effect addresses ROI. Philips' framework provides trainers a logical framework to view ROI both from human performance and business outcomes perspectives. However, the measurement goes further, comparing the monetary benefit from the programme with its costs. Although the ROI can be expressed in several ways, it is usually presented as a percent or cost/benefit ratio. While almost all HRD organisations conduct evaluations to measure satisfaction, very few actually conduct evaluations at the ROI level, perhaps because ROI is often characterised as a difficult and expensive process.

Since Kirkpatrick established his original model, other theorists and indeed Kirkpatrick himself, have referred to fifth level, namely ROI (Return on Investment). But ROI can easily be included in Kirkpatrick's original fourth level 'Result'. The inclusion and relevance of the fifth level is therefore arguably only relevant if the assessment of return on investment might otherwise be ignored or forgotten when referring simply to the 'Result' level.

There are some other training approaches and models. As it has been discussed earlier that training evaluation itself is less touched part of training and development, these methods have theoretical side but less in practical application. So these models are not discussed in detail. These are: Training Validation System (TVS) approach (Fitz-Enz, 1994), Input, Process, Output/ Outcome (IPO) Model (Bushnell, 1990), Hassett's training investment analysis approach; Kaufman's five level evaluation model, Mahapatra and Lai (2005) and Sadri and Synder (1995).

Hassett's training investment analysis approach focuses on the four important areas and measures the training effectiveness i.e. need analysis, information gathering, analysis and dissemination. Kaufman's five level evaluation model extends the scope of training impact evaluation beyond the organisation, it includes how training benefits the society and the surrounding environment in the organisation.

Table 1: Kaufman's five-level Evaluation

\begin{tabular}{|l|l|}
\hline Level & Evaluation Area \\
\hline 1.a. Enabling & Quality input availability like; human, financial and physical resources \\
\hline 1.b. Reaction & Methods, means and process acceptability and efficiency \\
\hline 2. Acquisition & Individual and small group mastery and competency \\
\hline 3. Application & Individual and small group utilization within the organisation \\
\hline 4. Organisational Output & Payoff to the organization \\
\hline 5. Societal Outcomes & Payoff to the society \\
\hline
\end{tabular}

Source: Adapted from Bhattacharyya, Dipak. Kumar. Human Resource Research Methods. Ganga. Saran \& Grand Sons. 2007. P - 266

Mahapatra and Lai (2005) stated that end user training can be evaluated at five levels. The five levels are; technology, reaction, skill acquisition, skill transfer and organisational effect. In assessing change that occurs after a period of training, researchers may tap one or all of three conceptually different kinds of change: alpha, beta and gamma (Sadri and Synder, 1995). In alpha change, the participant's report of change is unbiased between time one and time two (the pre- andpost-ratings) because it is based on an instrument that that has been continuously calibrated. Beta change refers to an apparent change where the measuring instrument has been recalibrated by the participant during the measurement intervals, i.e. individual perceptions of the response scale have changed. Gamma change refers to a situation where the participant redefines or reconceptualises some relevant information (Iyer at. el., 2009). 


\section{Conclusions}

Training evaluation is the most important aspect of training and development. It is a subject which has been much discussed but superficially carried out. There are various reasons for that which has been discussed earlier. One of the main reasons is that all models are descriptive and subjective in nature, its indicators for evaluating training and development is not clearly given and explained. From the above discussion it has been found out that Kirkpatrick model is widely used model at reaction level but in this case also what should be the main indicators at reaction level and other levels is not explained properly. So after discussing a lot on the models for evaluating training and development, it can be suggested that there are enough model for training evaluation. They should be further modified by giving its main indicators and explained properly about each issue so that evaluation of training and development can be properly carried out with greater effectiveness.

\section{References}

[1] B. Bowes, Employees Development Programs Help Companies Achieve Greater Success, CMA MANAGEMENT, 2008. 13-14.

[2] T. T. Baldwin, and J. K. Ford, Transfer of Training: A Review and Directions for Future Research, Personnel Psychology, 41(2), 1998.

[3] Gopal, Effectiveness of Executive Training Programs, The Indian Journal of Commerce, 61(3), 2008, $143-150$.

[4] V. Nagar, Measuring Training Effectiveness, The Indian Journal of Commerce, 62(4), 2009, 86-90.

[5] J. Philips, Handbook of training evaluation and measurement methods (Butterworth- Heinemann, Oxford, 1991).

[6] B. Holli, and R. Calabrese, Communication and education Skills for dietetics professionals Philadelphia: Lippincott, Williams \& Wilkins, 1998).

[7] J. Boulmetis, and P. Dutin, The abc's of evaluation: Timeless techniques for program and project managers (San Francisco, JosseyBass, 2000).

[8] U. F. Schalock, Outcome Based Evaluations (Boston, Kluwer Academic/Plenum, 1998).

[9] R. A. Noe, Employees Training and Development (Irwin, Mc Graw - Hill, 2008).

[10] L. M. Prasad, Human Resource Management (New Delhi, Sultan Chand \& Sons, 2005).

[11] R. Ramachandaran, Effectiveness of training programs of NLC - An Analysis, Kegees Journal of Social Science, 2(1), 2010, 119129.

[12] T. Saharan, Objective for Training: What Employees Perceive in Service Industry, Kegees Journal of Social Science, 3(1), 2011, $118-127$.

[13] A. Smith, Evaluation of Management Training -Subjectivity and the Individual, Journal of European Industrial Training, 14(1), 1990 .

[14] J. Hashim, Training Evaluation: Client's Roles, Journal of European Industrial Training, 25(7), 2001, 374 - 397.

[15] R. P. Griffin, Means and ends: effective training evaluation, Industrial and Commercial Training, 42(4), $2010,220-225$.

[16] M. M. AL-Ajlouni, M. H. S. Athamneh, and A. A. Jaradat, Methods of Evaluation: Training Techniques International Research, Journal of Finance and Economics, 37, 2010, 56-65.

[17] O. A. Ogundeji, Assuring the Quality of Training through Evaluation: A Model, Journal of Managerial Psychology, 6(1), $1991,3-11$.

[18] J. W. Hunt, and Y. Baruch, Developing top managers: the impact of interpersonal skills training, Journal of Management Development, 22(8), 2003, 729-752.

[19] A. A. Athari, and M. Zairi, Training Evaluation: An Empirical Study in Kuwait, Journal of European Industrial Training, 26(5), 2002, 241-251.

[20] R. Iyer, P. Pardiwalla, and J. Bathia, Training Evaluation Practices in Indian Organizations, HRD News Letter, 25 (8), 2009 , 35-37.

[21] P. N. Blanchard, J. W. Thacker, and S. A. Way, Training Evaluation: Perspective and Evidence from Canada, Indian Journal of Industrial Relations, 33(3), 2000, 295-304.

[22] M. A. Ogunu, Evaluation of Management Training and Development Program of Guinness Nigeria PLC, Indian Journal of Training and Development, 32(1), 2000, 22-28.

[23] K. B. L. Srivastava, S. Deb, and A. P. Prasad, Evaluating Training Effectiveness and Customer Satisfaction in Tata Steel: A Case Study, Indian Journal of Training and Development, 1(1), 2001, 45-56.

[24] D. Bramely, and A.C. Newby, The Evaluation of Training Part I: Clarifying the Concept, 8, $1984,10-16$.

[25] R. Sim, Evaluating Public Sector Training Programs, Public Personnel Management, 22(8), 1993,35 - 37.

[26] L. J. Bassi, and S. Cheney, Benchmarking the Best, Training and Development, 5(11), 1997, 60-64.

[27] S. Mann, and L. T. Robertson, What Should Training Evaluations Evaluate, Journal of European Industrial Training, $20(9), 1996,14-20$.

[28] J. H. Anthul, and I. G. Casper, Comprehensive Evaluation Model: A tool for the evaluation of non traditional education programs, Innovative Higher Education, 11(1), 1986, 55-64.

[29] D. G. Robinson, and T. C. Robinson, Training for impact: How to link training to business needs and measure the result (Sanfrancisco, Jossy: Bass, 1989).

[30] M. E. Smith, and D. C. Brandenburg, Summative Evaluation, Performance Improvement Quarterly, 4(2), 1991, 35-58.

[31] B. R. Worthen, and J. R. Sanders, Educational Evaluation. Alternative Approaches and Practical Guidelines, (New York, Longman, 1987).

[32] B. R. Worthen, \& J. R. Sanders, and J. L. Fitzpatrick, Program Evaluation: Alternative Approaches and Practical Guidelines (New York, London, 1997).

[33] Y. C. Jeng, and P. C. Hsu, Establishment of Evaluation Indicators for Student Practical Training in Insurance Industry. Retrieved March 15, 2010 from http://conference.nic.edu.sg/paper/converted\%20pdf/ab00288.pdf.

[34] D. L. Stufflebeam, Evaluation Models (San Francisco, Jossey - Bass, 2001).

[35] P. Warr, M. Bird, and N. Reckham, Evaluation of Management Training (London, Gower Press, 1970)

[36] C. Tennant, R. M. Boonkrong, A. B. Paul, The Design of a Training Program Measurement Model, Journal of European Industrial Training, 26(5), 2002, 230-240.

[37] A. Santos, and M. Stuart, Employees Perceptions and Influence on Training Effectiveness, Human Resource Management Journal, 13(1), 2003, 27-45.

[38] J. Phillips, Accountability in Human Resource Management (Butterworth- Heinemann, Oxford, 1996).

[39] C. James, and I. Roffe, The evaluation of goal and goal free training innovation, Journal of European Industrial Innovations, 24(1), 2000, 12-26.

[40] R. Mahapatra, and V. Lai, Evaluating End-User Training Programs, Communication of the ACM, 48(1), 2005 67-70.

[41] G. Sadri, and P. Snyder, Methodological issues in assessing training effectiveness, Journal of Managerial Psychology, 10(4), 1995, 30-32. 